Article

\title{
Diversity is not the Enemy: Promoting Encounters between University Students and Newcomers
}

\author{
Janieta Bartz $^{1, *}$ and Wibke Kleina ${ }^{2}$ \\ ${ }^{1}$ Department of Social and Emotional Development in Rehabilitation and Education, Faculty of Rehabilitation Sciences, \\ TU Dortmund, Germany; E-Mail: janieta.bartz@tu-dortmund.de \\ 2 Institute of General Didactics and School Pedagogy, Faculty of Educational Sciences and Psychology, TU Dortmund, \\ Germany; E-Mail: wibke.kleina@tu.dortmund.de \\ * Corresponding author
}

Submitted: 31 January 2021 | Accepted: 16 April 2021 | Published: 21 July 2021

\begin{abstract}
In today's globalized world with dynamic processes of political, social, and societal change (Mergner et al., 2019) the university should be a place of encounter between people with different (cultural) backgrounds. The learning arrangement presented here therefore initiates intercultural exchange and aims to help students see diversity as an asset rather than a challenge (Roos, 2019). To this end, an intercultural project was initiated at TU Dortmund in Germany in 2017. In the context of different learning environments future teachers were invited to have encounters with young newcomers through a nearly completely self-managed learning arrangement. The students were prepared for the encounters in focused courses dealing with theoretical backgrounds and didactic concepts. They would then prepare the lessons with the newcomers. In the context of this learning arrangement the following questions were important: What did the university students expect with regard to the encounter with newcomer students from schools? How did they prepare the lessons? What did students and newcomers think about the encounters later? What have they learned? And what do these reflections mean for inclusive and intercultural teacher education at universities? In the project we could observe that the didactic approach supports the students' level of sensitivity towards differences and encourages future teachers to train the education of newcomers in a non-judgmental framework (Bartz \& Bartz, 2018). Based on a selection of qualitative empirical findings (ethnographic approach during six lessons in a period of two years and 147 interviews including the students' and newcomers' points of view about their learning encounters at TU Dortmund), this article discusses opportunities to create more innovative spaces for inclusive practices and cultures under the restricted terms of a mass university.
\end{abstract}

\section{Keywords}

higher education; intercultural studies; guided encounters; newcomers; teacher education; reflective inclusion; refugees; self-reflection; universal design for learning

Issue

This article is part of the issue "Inclusive Universities in a Globalized World" edited by Liudvika Leišyte (TU Dortmund, Germany), Rosemary Deem (Royal Holloway, UK) and Charikleia Tzanakou (Oxford Brookes University, UK).

(C) 2021 by the authors; licensee Cogitatio (Lisbon, Portugal). This article is licensed under a Creative Commons Attribution 4.0 International License (CC BY).

\section{Introduction}

In Germany, as in many other parts of the world, globalization and migration have led to an increasing influx of students from different (cultural) backgrounds in schools and universities. The student body is very diverse, with students speaking different languages and having different religious or ethnical backgrounds (Florian, 2017, p. 11). Particularly in the context of teacher training, it is important to help future teachers to use this diversity as an opportunity. Research conducted in this field shows that many teachers already have positive attitudes 
towards heterogeneous student groups (Ruberg \& Porsch, 2017) but are struggling with the practical tasks in school (Grimm \& Schlupp, 2019). So, there is still a big gap between the theoretical idea of seeing a heterogeneous student body as an educational resource rather than an excessive burden and the practical implementation of this idea. Particularly in the case of teaching newcomers, this well-known gap becomes highly relevant. Recent studies call attention to the fact that teachers feel unprepared to teach newcomers, have many insecurities about teaching them and are struggling with increased learning demands like language support (e.g., Bačáková \& Closs, 2013; Kipouropoulou, 2019; Lechner \& Huber, 2017). To put it in a nutshell, teaching refugee students is often perceived as a challenge for teachers (Kleina \& Ruberg, 2020). Apart from that, many refugee students face discrimination and experience racism in school systems (e.g., Block et al., 2014; Correa-Velez et al., 2016; Uptin et al., 2016). Thus, both educational systems and teachers must learn to adapt to the needs of newcomers. Consequently, teacher education programs in universities should offer possibilities to reflect on the fixed idea of newcomers as extraordinary students who are an additional burden in the classroom (Grimm \& Schlupp, 2019). Results of previous studies indicate that personal encounters with disadvantaged or marginalized learners can support teachers in having a more positive attitude towards them and encourage them to teach in more inclusive ways (Fichten et al., 2005; Seifried, 2015). Following the contact hypothesis formulated by Allport (1954), the facilitation of accompanied learning processes where students experience real learners, including their needs, and can see for themselves that there is no such thing as one homogenous group of newcomers with a single story to tell about them, entails a great opportunity for educational settings. It is quite important to underline that this experience works in both ways: Newcomers, for their part, get the opportunity to become more familiar with higher education settings, are invited to a new learning arrangement and can speak their own truth, if they like, instead of being addressed as passive and as people being in need (Brewer, 2016, p. 136).

These research findings encourage programs that provide teachers and refugees with appropriate insightful encounters and learning. So far, there has been insufficient research on how such programs can be designed in terms of content, didactics, and organization, and what outcomes can be expected (Bartz et al., 2018). This research gap is to be closed with this work. For this purpose, an explorative, qualitative research design was chosen in order to create the preconditions for larger-scale, hypothesis-testing studies in the future.

This article provides insights into an experimental seminar project at TU Dortmund in Germany that intends to help future teachers experience and reflect on cultural diversity in the context of higher education. In our research project, the future teachers and the newcom- ers are both included as target groups. The seminar project has an innovative approach to open the university towards the community and is connected to the local meeting center TU@Adam's Corner. Based on the concept of reflective inclusion and the use of the Universal Design for Learning (UDL) method, the seminar project contributes to reflective and difference-sensitive teacher education. By using the concept of reflective inclusion, we also try to think about stereotypes. We encourage students to talk about their thoughts honestly and reflect them together in the group. Thereby we try to avoid the possibility of participants remembering only the information that fits their existing views or stereotypes from the encounters.

The cooperation project introduced in this article is associated with the DoProfiL program (Dortmunder Profil für inklusionsorientierte Lehrerlnnenbildung), which focusses on inclusive teacher education at TU Dortmund. This project is part of the Qualitätsoffensive Lehrerbildung, a joint initiative of the Federal Government and the Länder which aims to improve the quality of teacher training. The program is funded by the Federal Ministry of Education and Research. The authors are responsible for the content of this publication.

\subsection{About Migration in Germany and First Intercultural Projects in Dortmund}

Germany has a long tradition of migration and therefore the topic of immigration is not new, but since 2015 the intensity and extent of migration have reached a different level. In that year, Germany recorded the highest rate of immigration in its history. One-third of the refugees coming to Germany were children and young adults (Statistisches Bundesamt, 2016). The city of Dortmund, the setting for the activities and methodological reflections presented here, is a place of encounter between different cultures. Like the entire region known since the 1920s as the Ruhr area, it has always and fundamentally been shaped by migration. The migration movements of recent years have brought many unaccompanied, underage refugees to the region and to Dortmund. For this reason, TU@Adam's Corner has been created in the city to facilitate the arrival of these young people. TU@Adam's Corner is a meeting place where learners and teachers jointly design a learning space for the international classes at Dortmund's vocational colleges. In these international classes, young refugees learn German together with other students who are new to Dortmund. Since February 2016, the project has been supplemented by TU@Adam's Corner: Scientists from TU Dortmund share their knowledge with young refugees and immigrants, and in this way open up perspectives of belonging, arriving and shaping the future. The main goal of this attached university organization is to take an active stance towards working with refugee students and help them getting to know their new surroundings, including local educational institutions. 


\section{Requirements for Teacher Education and Reflective Inclusion as the Main Concept}

Schools and universities play a significant role in facilitating the human right of education for all newcomers. In Germany, however, many universities are only just beginning to find appropriate ways to prepare students for teaching newcomers. Related topics like migration and critical race theories are still not part of the mainstream curriculum for teacher education (Karakaşoğlu et al., 2017). Nevertheless, future teachers should be prepared for the situation of diversity in German schools as early as possible. This is "a matter of social justice and equity in education" (Florian, 2017, p. 9) and should be addressed as a permanent task for educational systems. Particularly with the worldwide agenda of inclusive education there is an ongoing discussion about how teachers can learn to fully address the needs of all learners and how teacher education programs can support this goal. In this respect, the concept of (self)reflection is one of the most widely discussed ideas (Watkins, 2012). There is a broad agreement that it is the universities' task to create learning settings in which students can experience irritation, new ground, deal with possible misperceptions while being guided, and learn to frame their experiences with the help of scientific theory and by communicative exchange with peers and training staff. Inclusive education succeeds above all through reflection by all those involved in teaching processes (Beutel \& Pant, 2020). In particular, this is underpinned by the approach of reflective inclusion, which understands difference as a product of social interactions in which (dis)advantages are inscribed. Such an understanding requires a specific mode of reflection that comprises a permanent reflection on the individual consequences and structural conditions of one's own actions (Dannenbeck \& Dorrance, 2009). Being already a subject of general discussion as an important dimension of professionalism for teacher education, (self-)reflection is thus of significant importance for difference-sensitive teacher education as well. Such an approach involves the challenge of reflecting on school practice with regard to the (re-)production and processing of differences concerning cultural diversity as well as illuminating processes of stereotyping and othering (Ashcroft et al., 2000).

\subsection{Universal Design for Learning as a Method for Difference-Sensitive Higher Education}

One of the most promising methods for managing diversity in the classroom and for education in universities is the UDL (Powell \& Pfahl, 2018). This concept developed in the US can provide orientation in the planning and implementation of inclusive and difference-sensitive teaching. Based on the design concept of the same name, it highlights key points of a learning environment with as few barriers as possible, an environment that considers a variety of learning strategies and levels. Three basic prin- ciples ensure that learners can acquire knowledge and skills according to their individual requirements:

1. Offering various options for task processing (representation)

2. Design of active learning and expression possibilities (action and expression)

3. Enabling motivated learning (commitment)

One major main benefit of UDL is the fact that it provides a systematic guide for creating didactic settings. Given the documented insecurities about teaching newcomers who are still learning German, it seems to be especially important that future teachers feel capable of planning the didactic setting and use this highly structured method to gain confidence. The basic principles of UDL allow the students to anticipate difficulties in learning and find new creative ways of working with them. For instance, UDL gives a lot of inspiration to use easy language and different visualization methods.

\subsection{What We Do: Acknowledging Diversity through Guided Encounters between Future Teachers and Newcomers}

The basic idea of the seminar concept is to help students to prepare for the task of teaching newcomers. This includes reducing uncertainties, sensitizing the students towards different backgrounds of learners and creating a safe space for exchanges between future teachers and newcomers. These goals result in a two-pillar agenda with support in didactic techniques and guided (self-)reflection.

The 65 students involved in this project are studying to obtain a master's degree in special needs education. At the time of the encounters, they were in their first, second or third semester.

Over the last two years, 82 young newcomers have taken part in this project. Some of them came from Iraq, Syria, Eritrea or Afghanistan, others from Europe, e.g., from Poland or Albania. The participants had been in Germany for an average of ten months, and their language level at the time was between $\mathrm{A} 1$ and $\mathrm{A} 2$.

Prior to the encounters, the university students developed a teaching concept for a period of $90 \mathrm{~min}$ utes using UDL to deal well with the linguistic, cognitive and cultural diversity of the newcomers. They focused on the following:

1. The students decide on teaching topics on which the newcomers are motivated to work.

2. Both the students and the newcomers work in an action-oriented and product-oriented way.

3. After welcoming the group of $\mathbf{1 5}$ to 20 newcomers, the students divide them into small groups of up to 5 to allow for more intensive encounters.

4. The learning material used in class is clearly structured and explains German terms with the additional help of pictures. 
5. The newcomers receive a product that they can take home.

The following topics were worked on in our project: celebrations, happiness, school, healthy eating, leisure activities and games. They are very general and intended to invite the newcomers to share their experiences.

We always take an advisory and supportive role in creating the materials and preparing the lesson. As a rule, all lessons observed followed a similar schedule: Welcome and introduction of all participants (10 minutes), information about the respective topic and the structure of the lesson (5 minutes), work at different group tables (60 minutes) and discussion of the results (15 minutes). Small groups of 5 newcomers worked at a topic table at a time. This was supervised by 3-4 university students to ensure that a close and, if desired, personal exchange could take place. It is important to us that all participants meet with acknowledgment and allow personal conversations. In this way, people get to know each other more intensively and can exchange ideas more easily.

\section{Empirical Design: Research Questions, Materials and Methods}

For the accompanying research, we selected four guiding research questions to highlight different aspects of the seminar setting and to receive multi-perspective insights from students and newcomers (Table 1).

In order to gain differentiated insights into the learning processes, we chose to use a complex qualitative research design with different survey times (pre-post-design). The research sample includes all participants in the program a total of 147 individuals (65 students, 82 newcomers). The data was collected through ethnographic observation and semi-structured interviews. Thus, it was possible to obtain differentiated answers to our research questions by systematic observation, collecting materials in the field and subsequent documentation of the experiences through the participants (Flick, 2014, p. 302). The semi-structured interviews identified students' expectations and didactic considerations for the planned learning arrangement in combination with assumptions about the newcomers. In addition, the newcomers were asked about their expectations and wishes with regard to the upcoming encounter with the university students. Both groups of individuals were asked about their experiences during the post-encounter interviews. A special focus was placed on the learning processes that the subjects observed themselves going through. To document the encounters, observation protocols were used by the students and by us who observed the study. The following were central points of observation:

1. The manner of opening the encounter

2. The involvement of the newcomers during the first round of introductions

3. The type and intensity of the newcomers' involvement during the group work

4. Didactic success and failures of the students during the group work

5. Non-verbal communication

6. Changes in behavior or involvement of all individuals

An argument for using the ethnographic method was the uniqueness of the encounters. Although encounters between newcomers and students are organized every semester (usually one or two times), the participants and teaching concepts change every time. Thus, from the point of view of ethnographic research, it makes sense to be methodologically pragmatic and to document information and impressions comprehensively (Flick, 2014, p. 302).

The ethnographic data collected were analyzed deductively according to Mayring (2015) using three categories. These are for both target groups: (1) expectations, (2) arrangements, (3) learning experiences. The semistructured interviews conducted before and after the encounters were evaluated using a qualitative content analysis according to Mayring (2015). This procedure serves the purpose of reduction by systematically creating inductive and deductive categories from the given data. The main categories developed in this process are the basis for a typification of the observed results. Findings from the ethnographic data and the interviews are treated equally in the formation of categories.

Table 1. Research overview.

\begin{tabular}{lll}
\hline Focus & Method & Guiding research questions \\
\hline Expectation & $\begin{array}{l}\text { Ethnographic observation and } \\
\text { semi-structured interviews }\end{array}$ & $\begin{array}{l}\text { What do university students expect with regard to the } \\
\text { encounter with newcomer students from schools? }\end{array}$ \\
$\begin{array}{ll}\text { Didactic arrangement } & \begin{array}{l}\text { Ethnographic observation and } \\
\text { semi-structured interviews }\end{array}\end{array}$ & $\begin{array}{l}\text { How do they prepare the lessons for newcomers with } \\
\text { the help of UDL? }\end{array}$ \\
$\begin{array}{l}\text { Learning experience } \\
\text { on both sides }\end{array}$ & Semi-structured interviews & $\begin{array}{l}\text { What do students and newcomers think about the } \\
\text { encounters later? } \\
\text { What have they learned? }\end{array}$ \\
\hline
\end{tabular}




\section{Results}

As pointed out before, the research questions were divided into three categories: (1) expectations, (2) didactic arrangement and (3) learning experiences on both sides. Along these categories, the collected data from the ethnographic observations and the interviews is summarized.

\subsection{Expectations}

The expectations of the students prior to the encounters varied greatly and related to a wide range of feelings. Based on the evaluation of the interviews conducted with 65 students, three different types of student expectations were identified. There were students with no objections who seemed to be very open-minded in relation to teaching newcomers ( $5=$ type 1$)$, students with mixed feelings ( $35=$ type 2 ), and students who had major concerns (25 = type 3 ). This is rather surprising, because Dortmund is located in a region of Germany that is very multicultural. The chance of university students meeting newcomers at schools is rather high. Upon closer examination, it turned out that many students came from a section of society that can be described as affluent and not very intercultural. This could explain why many of them had intense feelings and concerns in the run-up to the encounter.

Only a minority of the students (5 out of 65 ) had had previous experiences with refugees in general. These students made a conscious decision to get involved in refugee work. A 21-year-old student, Laura, explained this in her interview:

I grew up very privileged. I am doing very well. I don't know what hunger, war or displacement means. But I know that as a teacher I will later encounter many children and young people who have had these hard experiences.... I don't want to do that unprepared. I want to get in touch with people like that while I'm still at university, which is why I help out in a school. I help [refugee] children with their homework and it gives me great pleasure.... That's why I'm looking forward to meeting the newcomers at our university.

Within the type 1 group, there is also a different kind of reasoning. For example, 20-year-old Luke said in the interview: "I am looking forward to meeting the newcomers. They are people who have had special experiences. But apart from that, they are people like you and me. If I approach them with an open heart, it will work out." So, he was very optimistic and open to new experiences. The latter also applied to the students from group type 2 . However, it also became clear in the interviews that even students who had had good experiences or were openminded used forms of othering: They often referred to newcomers as "these people" and displayed a very distant attitude. This dissociation may be due to a lack of personal encounters with refugees in their leisure time and in school settings. One student, Maria, explained it as follows:

I have little experience [as a teacher] and many questions. Especially, I have no experience with newcomers. The only thing I know is all the bad reports in the media. There is often talk on TV about Muslim boys not accepting women, even assaulting them. So I wonder how to protect myself from that.

This statement shows how the media have negatively influenced Maria's perceptions. This phenomenon was particularly evident among the type 3 students, who clearly expressed their fears and insecurities. For example, Markus said:

I don't know if we can do it. We all have no experience in school teaching. And many of us have no experience with newcomers. That's totally difficult. What do you do as a teacher if the newcomers don't respect you? Or what do I do if they don't understand me? I just can't imagine that it will be that easy.

Both students clearly pointed out fears associated with negative stereotyping of refugees, such as men being disrespectful towards women or refugee students lacking respect for authority figures. However, as said before, these students had not experienced this kind of behavior themselves; they seemed to have taken on these concepts from the media or from general public discourses. German media reports often create the impression of new immigration as a topos of danger (Geier \& Mecheril, 2021) and refugees are often marked as people who are unfamiliar with democratic values. This may be one reason why some of the students were so concerned about being respected by the newcomers. In addition to that, many students expected to hear stories of flight and very drastic accounts of war and conflict. However, the newcomers had very different backgrounds; some were from neighboring European countries, others from far away countries like Iraq; they all had different (flight) stories to tell and these were above all stories of resilience. What also became apparent were stereotype ideas of restricted gender roles, as Markus' statement points out:

We have chosen the theme of celebrations, and at my group table it'll be weddings. I really don't know how I'll react when young girls with headscarves tell me that they really want to get married when they are 16 or 17.

Other students expected the female newcomers to be "very shy" and to "need help from the students to be confident." They seemed to think of female newcomers as persons who are not confident and needy. This refers to a common discourse of refugees who are often seen as people in need and not as active participants (Brewer, 
2016). Other students also expressed prejudices towards newcomers, the most common being: a lack of German language skills, that their bad experiences in the past would affect them in teaching contexts and that they would be unfamiliar with regular school settings given their long absence from school.

It was important to us that the students had the opportunity to freely express their doubts and prejudices during the interviews and seminars and reflect on them with each other. In this exchange, it became apparent that type 1 students critically questioned many of the prejudices named by their peers. In some cases, we intervened to contradict prejudices that the newcomers should be protected from. For instance, many students thought that the newcomers did not want to know much about Germany at all because they would be going back home after the war. We used studies and official data to underline that these were misperceptions and that the schooling of newcomers is a task that goes beyond a short-term emergency (UNHCR, 2016). Otherwise, the students discussed their concerns, let some of them stand, and waited for the encounter with the newcomers.

\subsubsection{Didactic Arrangement}

We examined the didactic arrangement both ethnographically and through interviews. First, the results of our ethnographic observation: As mentioned before, the students worked with the inclusive method of UDL. They created different learning materials, formulated tasks, researched information, used pictures and symbols and did a lot of crafting. Besides, the students researched information from the newcomers' countries of origin and presented some of it in different languages. During the preparation, the students talked about how they would act in case of problems and gave each other hints. Didactically relevant questions asked by the students, such as "how good are the language skills?" and "can the newcomers read?" as well as decisions they had to make before the encounters indicate that they expected teaching newcomers to be a challenge. These questions can be explained by the uncertainty of the students. On the one hand, they had little experience of teaching schoolchildren and on the other, they had little or no experience with language learners or newcomers. The interviews revealed, however, that with the detailed preparation of the material according to the UDL guidelines the students' uncertainty diminished and they felt well prepared. All of them pointed out that the preparation involved an enormous amount of time, which they had not expected. However, they agreed that this would make the meeting all the better. From our experience, these lessons generally run very well in all semesters and the good preparation allows the lessons to proceed in a structured way. According to our observations, everyone involved in the situation feels comfortable, and inspired conversations arise. Furthermore, it turns out that the newcomers are not the only ones who learn something.

\subsubsection{Learning Experiences on Both Sides}

From the ethnographic perspective, it can be stated that the students reacted mainly with surprise, pleasure in teaching and relief about well-functioning processes. Only two participants in the sample were not surprised or not satisfied with the results. This is also evident in the interviews. For example, Maria told us:

I have learned so much. I am so happy that there were no problems at all.... Honestly, I feel ashamed that I thought so badly about male Muslim newcomers. We were talking about school, and they explained to me that in Islam you treat every teacher respectfully. It doesn't matter if it's a man or a woman. They were so polite and kind to me. I was really pleased, and now I find it really embarrassing that I was so unreflective before. But precisely because I had such prejudices, this encounter is so precious to me.

Like Maria, Mark also had an unexpected experience:

I was at the group table on the topic of marriage. And I told them that Germans often marry later than people in other cultures. Then a girl comes forward and says that she doesn't want to get married until she's 30 or so. Definitely not earlier. I was totally surprised and asked her why that was so important to her....She said that in her home country women are oppressed and she doesn't want that. She is now in Germany and wants to graduate from high school and go to university. She wants to take care of herself and only then look for a handsome man....When she said that, I realized that I hadn't expected her to be so selfconfident and take her life into her own hands like that....This experience showed me that l'd had pretty strong prejudices. But it is important to get involved with people individually. That's what I've learned.

We also interviewed the newcomers who met Mark and Maria. Sahid said about his meeting with Maria:

Maria will be a very good teacher. She was very friendly to us....We talked about school in Syria and about teachers. Then we told her that we Muslims pay special attention to teachers because they put a lot of effort into teaching us. She was very happy about that. After that it was really good. We laughed a lot and talked about our school days....And I got to know the university. I would like to become a teacher one day and I have already met some nice colleagues. Now I really feel like doing my Abitur and studying.

We also asked Lilas about her encounter with Mark. She said:

It was so much fun to learn about German weddings. I didn't know all the traditions. But there are also 
things we all have in common: good food, friends and relatives....It was funny when I told him that I would never get married before I was 30. I think Mark was very surprised. I find that funny, because why should a woman marry early and have children? I think he watched too much television. But it's good if a teacher knows that we girls want to study and not get married right away. I think he also learned something important.

These statements from Lilas and Sahid reflect the overall perceptions of the newcomers. The interviews show that they have learned a lot about German festivities and focused on the similarities to their own traditions. It was a lot of fun and encouraging for them to see the university is reachable, both through the regional proximity, but also through the shared learning experience. Most of them showed self-confidence and saw themselves as people who have enriched the teaching processes. This is especially evident in their joyful realization that the students have also learned something from them. They find this eye-to-eye encounter very important, because in their everyday lives, their experiences are different, especially with public authorities and administrations. Sadly, and shockingly, their reports have in common that they often encounter people who are prejudiced towards them. One newcomer summed it up: "Finally I am being treated as an intelligent person and not like a stupid animal. The students have done a really good job and I feel welcome."

\section{Discussion and Conclusion}

The results can be summarized in five main points:

1. Even though the future teachers are studying in a multicultural city, only five of them have reached out to newcomers before.

2. 60 of the 65 students interviewed expressed (major) worries, fears and even prejudices before the encounter.

3. The encounter itself was evaluated as fruitful and educative by nearly all participants.

4. The 82 newcomers interviewed had a positive view of the past encounter, 45 of them feel motivated to study in Germany and all interviewed newcomers felt very welcome and liked the open dialogue.

5. Type 2 and type 3 students pointed out that the encounter with the newcomers was very meaningful for them and that their previously negative perspective has changed significantly.

Looking at these results, the importance of guided encounters in the context of inclusive and intercultural educational processes becomes clear. Learning and reflection processes among the university students were only initiated by real encounters with newcomers. The project revealed that the majority of the stu- dents had had no contact points with refugees before, but many negative assumptions. In part, the students' monocultural social environment and the predominantly negative media reports on migration may explain these findings (Geier \& Mecheril, 2021). After meeting the newcomers many students questioned their views and learned to see the individual instead of an imagined group. Therefore, this encounter is not only instructive in terms of the content imparted, but above all through the personal interaction. The basis of this interaction is simple but important: strengthening commonalities and understanding particularities. For teacher education, these findings imply the need to regularly examine the extent to which students have had intercultural experiences. In our view, for the students' future work in inclusive German schools it is imperative for them to have already made and reflected on first experiences during their studies.

Regarding the newcomers interviewed, our project has also shown some interesting and disturbing findings. Obviously, a large proportion (45 of 82) have had mainly bad experiences in interactions with public authorities and administrations. In contrast, they describe the encounter with the students as enriching and consider this special, because it took place in a public institution as well. It is rather alarming that the majority of the newcomers regarded it as exceptional to be welcomed and to be treated as equals, but certainly this is no isolated case (Brewer, 2016; Seukwa, 2007).

A relevant encounter also needs to be well prepared methodically. Studies underline that not the encounter itself is of importance but rather the quality of the experience (Urton et al., 2015). Based on the ethnographically collected data, we were able to determine that the differentiated preparation with UDL supported lively discussions and made the active participation of all newcomers possible. These controlled conditions give the students greater confidence in their actions, which is particularly important when they first come into contact with teaching (newcomers). Of course, the concept does not guarantee success, but the students learn how to deal more competently with heterogeneous learning requirements. They learn not only at the personal, but also at the methodical level: Diversity is not the enemy. In fact, from the results it is clear for us that one encounter alone has made a major difference for the students involved. Nevertheless, it is essential that such encounters are well accompanied. There is a need for reflection spaces in order to critically question one's own (professional) actions (self-reflection) and to learn new skills (didactic competence).

However, the results should also be viewed in light of the limitations of our research. We did not conduct a representative study that would allow for generalizations, and we cannot say anything about long-term effects. Our focus was on the individual experiences and encounters and the accompanying reflective processes that the interviewees went through. Our research is understood 
as an exploratory design, which invites further (quantitative) research. This is especially important if meaningful results on changes of students' attitudes towards newcomers are to be collected. For future studies, we would recommend the objective measurement of attitude changes.

\section{Acknowledgments}

Thanks to Rebecca Steffen and Lisa Paluda for the great support with the linguistic revision of this article.

\section{Conflict of Interests}

The authors declare no conflict of interests.

\section{References}

Allport, G. W. (1954). The nature of prejudice. AddisonWesley.

Ashcroft, B., Griffiths, G., \& Tiffin, H. (2000). Post-colonial studies: The key concepts. Routledge.

Bačáková, M., \& Closs, A. (2013). Continuing professional development (CPD) as a means to reducing barriers to inclusive education: Research study of the education of refugee children in the Czech Republic. European Journal of Special Needs Education, 28(2), 203-216.

Bartz, J., \& Bartz, T. (2018). Recognizing and acknowledging worldview diversity in the inclusive classroom. Education Science, 8(4), 196.

Bartz, J., Delucchi Danhier, R., Mertins, B., Schüppel, K. C., Welzel, B., \& Zimenkova, T. (2018). Auf dem Weg zur Neuverortung: Sprache, Objektkultur und Religion im transkulturellen Deutschland [Towards a repositioning: Language, object culture and religion in transcultural Germany]. In S. Hußmann \& B. Welzel (Eds.), DoProfil-Das Dortmunder Profil für inklusionsorientierte Lehrer/-innenbildung [Dortmund profile for inclusion-oriented teacher education] (pp. 179-193). Waxmann.

Beutel, S.-I., \& Pant, H. A. (2020). Lernen ohne Noten. Alternative Konzepte der Leistungsbeurteilung [Learning without grades. Alternative concepts of performance evaluation]. Kohlhammer.

Block, K., Cross, S., Riggs, E., \& Gibbs, L. (2014). Supporting schools to create an inclusive environment for refugee students. International Journal of Inclusive Education, 18(12), 1337-1355.

Brewer, C. A. (2016). An outline for including refugees in Canadian educational policy. Canadian Journal for New Scholars in Education, 7(1), 133-141.

Correa-Velez, I., Gifford, S., McMichael, C., \& Sampson, R. (2016). Predictors of secondary school completion among refugee youth 8 to 9 years after resettlement in Melbourne, Australia. Journal of International Migration and Integration, 18(3), 791-805.

Dannenbeck, C., \& Dorrance, C. (2009). Inklusion als
Perspektive (sozial)pädagogischen Handelns-Eine Kritik der Entpolitisierung des Inklusionsgedankens [Inclusion as a perspective of (socio)pedagogical action: A critique of the depoliticization of the idea of inclusion]. Zeitschrift für Inklusion, 3(2). http:// bidok.uibk.ac.at/library/inkl-02-09-dannenbeckinklusion.html

Fichten, C. S., Schipper, F., \& Cutler, N. (2005). Does volunteering with children affect attitudes toward adults with disabilities? A prospective study of unequal contact. Rehabilitation Psychology, 50(2), 164-173.

Flick, U. (2014). Qualitative Sozialforschung: Eine Einführung [Qualitative social research: An introduction]. Rowohlt.

Florian, L. (2017). Teacher education for the changing demographics of schooling. Inclusive education for each and every learner. In L. Florian \& N. Pantić (Eds.), Teacher education for the changing demographics of schooling (pp. 9-20). Springer.

Geier, T., \& Mecheril, P. (2021). Grenze, Bewegung, Beunruhigung. Skizze einer zugehörigkeitstheoretisch informierten Migrationsforschung [Border, movement, disquiet. Migration research in the framework of belonging theory]. Journal of Migration Studies, 1(1), 171-196. https://doi.org/10.48439/zmf. v1i1.104

Grimm, M., \& Schlupp, S. (2019). Flucht und Schule. Herausforderungen der Migrationsbewegung im schulischen Kontext [Refugees and schools: Migrationrelated challenges in the context of schools]. Beltz.

Karakaşoğlu, Y., Mecheril, P., Shure, S., \& Wojciechowicz, A. A. (2017). Angekommen in der Migrationsgesellschaft. Grundlagen der Lehrerbildung auf dem Prüfstand [Having arrived in migration society: Putting fundamentals of teacher training to the test]. Stiftung Mercator. https://www.wissensatlasbildung.de/publikation/angekommen-in-dermigrationsgesellschaft-grundlagen-derlehrerbildung-auf-dem-pruefstand

Kipouropoulou, E. (2019). Primary school teachers' perceptions about refugee children inclusion in Greek schools: Are teachers prepared? Sino-US English Teaching, 16(6), 240-248. http://www.david publisher.org/Public/uploads/Contribute/ 5d355fd2f0537.pdf

Kleina, W., \& Ruberg, C. (2020). "Schule im Kontext von Flucht": Bestandsaufnahme und Perspektiven der Forschung ["Schools in the context of migration": Research review and perspectives]. In K. Banz, W. Beutel, M. Förster, \& J. Schindler (Eds.), Geflüchtete in der Lehrerbildung. Miteinander Demokratie lernen [Refugees in English teacher educationLearning democracy together] (pp. 123-136). Debus Pädagogik.

Lechner, C., \& Huber, A. (2017). Ankommen nach der Flucht. Die Sicht begleiteter und unbegleiteter Geflüchteter auf ihre Lebenslagen in Deutschland 
[Arriving after the escape: The views of accompanied and unaccompanied refugees on their life situation in Germany]. Deutsches Jugendinstitut.

Mayring, P. (2015). Qualitative Inhaltsanalyse. Grundlagen und Techniken [Qualitative content analysis: Basic ideas and techniques] (12th ed.). Beltz.

Mergner, J., Leisyte, L., \& Bosse, E. (2019). The widening participation agenda in German higher education: Discourses and legitimizing strategies. Social Inclusion, 7(1), 61-70.

Powell, J. J. W., \& Pfahl, L. (2018) Disability studies in the universal design university. In S. K. Gertz, B. Huang, \& L. Cyr (Eds.), Diversity and inclusion in higher education and societal contexts: international and interdisciplinary approaches (pp. 157-188). Palgrave Macmillan.

Roos, H. (2019). Challenges at the border of normality: Students in special educational needs in an inclusive mathematics classroom. In J. Subramanian (Ed.), Proceedings of the tenth international mathematics education and society conference: Mathematics Education and Society, Hyderabad, India (pp. 928-940). Mathematics Education and Society.

Ruberg, C., \& Porsch, R. (2017). Einstellungen von Lehramtsstudierenden und Lehrkräften zur schulischen Inklusion. Ein systematisches Review deutschsprachiger Forschungsarbeiten [Attitudes of student teachers and teaching staff towards inclusion in schools. A systematic review of Germanlanguage research papers]. Zeitschrift für Pädagogik, 63(4), 393-415.

Seifried, S. (2015). Einstellungen von Lehrkräften zu Inklusion und deren Bedeutung für den schulischen Implementierungsprozess-Entwicklung, Validierung und strukturgleichungsanalytische Modellierung der Skala EFI-L [Teachers' attitudes towards inclusion and their significance for the implementation process in schools: Development, validation and structural equation modelling of the EFI-L scale; unpublished doctoral dissertation]. Pädagogische Hochschule Heidelberg. https://opus.ph-heidelberg. de/frontdoor/deliver/index/docld/140/file/

Dissertation_Seifried_Stefanie.pdf

Seukwa, L. H. (2007). The ingrained art of survival: The nexus between competence and migration as reflected in refugee biographies. Rüdiger Köppe.

Statistisches Bundesamt. (2016, July 14). 2015: Höchststände bei Zuwanderung und Wanderungsüberschuss in Deutschland [2015: Immigration numbers at record highs and immigration surplus in Germany; Press Release]. https://www.destatis.de/DE/ Presse/Pressemitteilungen/2016/07/PD16_246 12421.html;jsessionid=17AC049455FF46456677134 E1AF3368C.internet8732

UNHCR. (2016). No more excuses: Provide education in all forcibly displaced people. UNESDOC Digital Library. https://unesdoc.unesco.org/ark:/48223/ pf0000244847

Uptin, J., Wright, J., \& Harwood, V. (2016). Finding education. Stories of how young former refugees constituted strategic identities in order to access school. Race, Ethnicity and Education, 19(3), 598-617.

Urton, K., Wilbert, J., \& Hennemann, T. (2015). Die Einstellung zur Integration und die Wirksamkeit von Lehrkräften [The attitude towards integration and the effectiveness of teachers]. Psychologie in Erziehung und Unterricht, 62(2), 147-157.

Watkins, A. (Ed.). (2012). Inklusionsorientierte Lehrerbildung. Ein Profil für inklusive Lehrerinnen und Lehrer [Teacher education for inclusion: A profile of inclusive teachers]. European Agency for Development in Special Needs Education.

\section{About the Authors}

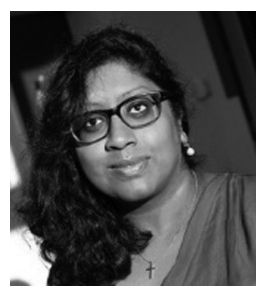

Janieta Bartz is a Researcher and Lecturer at the Department of Social and Emotional Development in Rehabilitation and Education of the Faculty of Rehabilitation Sciences, TU Dortmund. In teaching and research, her work focuses primarily on inclusive (higher) education, disability studies and worldview diversity in educational settings.

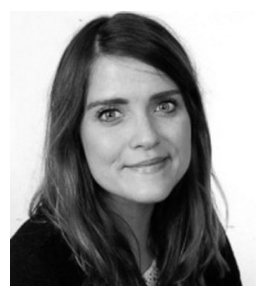

Wibke Kleina has been working as a Research Assistant at the Institute of General Didactics and School Pedagogy at TU Dortmund since 2015. In teaching and research, her work focuses on teacher training for inclusion, migration and education, development of schools and teaching concepts. Since 2017, she has been participating in a project on the development of schools and teaching concepts as part of the educational initiative "RuhrFutur-2. Phase." 